Pacific Journal of Mathematics

A HELLINGER INTEGRAL REPRESENTATION FOR BOUNDED 


\title{
A HELLINGER INTEGRAL REPRESENTATION FOR BOUNDED LINEAR FUNCTIONALS
}

\author{
JAMES R. WEBB
}

\begin{abstract}
The function space considered is that consisting of the complex-valued, quasicontinuous functions on a real interval $[a, b]$, anchored at $a$, and having the $L U B$ norm. It is shown that each bounded linear functional on this Banach space has a Hellinger integral representation. A formula for the norm of the functional is given in terms of the integrating functions involved in its representation. A new existence criterion for the Hellinger integral is uncovered on the way to the representation theorem.
\end{abstract}

2. Definitions. In this section certain definitions and notational conventions are adopted for use in the succeeding sections. Throughout the paper, $[a, b]$ will denote a given interval and the word function will mean map from $[a, b]$ into the complex numbers.

Definition 2.1. If $c$ is any number in $(a, b]$, then $R_{c}$ denotes a function such that $R_{c}(t)=0$ if $t$ is in $[a, c)$ and $R_{c}(t)=1$ if $c \leqq t \leqq b$. If $c$ is in $[a, b)$, then $L_{c}$ denotes a function such that $L_{c}(t)=0$ if $a \leqq t \leqq c$ and $L_{c}(t)=1$ is $t$ is in $(c, b]$. The functions $L_{c}$ and $R_{c}$ are called unit step functions. A linear combination of unit step functions is called a step function. Notice that each step function vanishes at $a$.

Definition 2.2. We now specify the function space, $Q_{0}[a, b]$, which plays the central role. Its elements are the quasicontinuous functions anchored at $a$ and they may be defined in two ways. First, $Q_{0}[a, b]$ is the set of all functions which vanish at $a$ and which have a limit from the right at each $t$ in $[a, b)$ and a limit from the left at each $t$ in $(a, b]$. Second, let $B[a, b]$ be the Banach space of bounded functions, with $L U B$ norm. Then $Q_{0}[a, b]$ is the closure, in $B[a, b]$, of the linear space of all step functions. So $Q_{0}[a, b]$ is a Banach space with norm $\|x\|=L U B|x(t)|$ for all $t$ in $[a, b]$. Also, each bounded linear functional on $Q_{0}[a, b]$ is determined by its values on the step functions, since the latter form a dense linear subspace.

For proof of the equivalence of these two formulations of $Q_{0}[a, b]$, see [1, Lemma 4.16].

Definition 2.3. Suppose $g$ is any subset of $[a, b]$. If $x$ is a function, then $x_{g}$ denotes a function such that $x_{g}(t)=x(t)$ if $t$ is in $g$ 
and $x_{g}(t)=0$ if $t$ is in $[a, b]$ but not in $g$. If $F$ is a linear functional defined on $Q_{0}[a, b]$ and it is true that $x_{g}$ is in $Q_{0}[a, b]$ for each $x$ in $Q_{0}[a, b]$, then $F_{g}$ denotes a linear functional such that $F_{g}(x)=F\left(x_{g}\right)$ for each $x$ in $Q_{0}[a, b]$.

DeFinition 2.4. " $v$ has bounded slope variation with respect to $u$ " means that $v$ is a function, $u$ is a real-valued, increasing function, and there exists a nonnegative number $B$ such that if $\left\{t_{p}\right\}_{p=0}^{n}$ is a subdivision of $[a, b]$ with $n>1$, then

$$
\sum_{p=1}^{n-1}\left|\frac{v\left(t_{p+1}\right)-v\left(t_{p}\right)}{u\left(t_{p+1}\right)-u\left(t_{p}\right)}-\frac{v\left(t_{p}\right)-v\left(t_{p-1}\right)}{u\left(t_{p}\right)-u\left(t_{p-1}\right)}\right| \leqq B .
$$

The least such number $B$ is denoted by $V_{a}^{b}(d v / d u)$ and is called the slope variation of $v$ with respect to $u$ over $[a, b]$.

Definition 2.5. Suppose each of $u, v$, and $w$ is a function and $u$ is increasing. "The Hellinger integral $\int_{a}^{b} d w d v / d u$ exists" means that $\int_{a}^{b} d w d v / d u$ is a number and for each positive number $\varepsilon$ there exists a subdivision $D$ of $[a, b]$ such that if $\left\{t_{p}\right\}_{p=0}^{n}$ is any refinement of $D$ then

$$
\left|\int_{a}^{b} \frac{d w d v}{d u}-\sum_{p=1}^{n} \frac{\left[w \left(t_{p}\left(-w\left(t_{p-1}\right)\right] \cdot\left[v\left(t_{p}\right)-v\left(t_{p-1}\right)\right]\right.\right.}{u\left(t_{p}\right)-u\left(t_{p-1}\right)}\right|<\varepsilon
$$

Clearly, this integral has a unique value.

DEFINITION 2.6. If $u$ is an increasing function and $v$ is a function and $c$ is in $[a, b)$ then " $D_{u}^{+} v(c)$ exists" means that

$$
\operatorname{limit}_{t \rightarrow c+} \frac{v(t)-v(c)}{u(t)-u(c)}
$$

exists and equals $D_{u}^{+} v(c)$. The notation $D_{u}^{-} v(c)$ is used in a corresponding manner for numbers $c$ in $(a, b]$.

3. Lemmas. This section contains results which are used in the proofs given for theorems in $\S 4$.

LEMMA 3.1. If $n$ is an integer greater than 2 and $k_{0}, k_{1}, \cdots, k_{n}$ is a sequence of complex numbers and $e_{1}, e_{2}, \cdots, e_{n}$ is a sequence of positive real numbers then

$$
\begin{aligned}
& \sum_{p=1}^{n-1}\left|\frac{k_{p+1}-k_{p}}{e_{p+1}}-\frac{k_{p}-k_{p-1}}{e_{p}}\right| \\
& \quad \geqq \frac{1}{e_{n}}\left(\sum_{q=1}^{n} e_{q}\right)\left|\frac{k_{n}-k_{0}}{\sum_{q=1}^{n} e_{q}}-\frac{k_{n-1}-k_{0}}{\sum_{q=1}^{n-1} e_{q}}\right|+\sum_{p=1}^{n-2}\left|\frac{k_{p+1}-k_{0}}{\sum_{q=1}^{p+1} e_{q}}-\frac{k_{p}-k_{0}}{\sum_{q=1}^{p} e_{q}}\right|
\end{aligned}
$$


Proof by induction. For the case $n=3$,

$$
\begin{aligned}
& \left|\frac{k_{3}-k_{2}}{e_{3}}-\frac{k_{2}-k_{1}}{e_{2}}\right|+\left|\frac{k_{2}-k_{1}}{e_{2}}-\frac{k_{1}-k_{0}}{e_{1}}\right| \\
& =\left|\frac{k_{3}-k_{2}}{e_{3}}-\frac{k_{2}-k_{1}}{e_{2}}\right|+\frac{e_{1}}{e_{2}}\left|\frac{k_{2}-k_{0}}{e_{1}+e_{2}}-\frac{k_{1}-k_{0}}{e_{1}}\right| \\
& \quad+\left|\frac{k_{2}-k_{0}}{e_{1}+e_{2}}-\frac{k_{1}-k_{0}}{e_{1}}\right| .
\end{aligned}
$$

But by the triangle inequality, the sum of the first two terms of the right-hand member is greater than or equal to

$$
\begin{aligned}
& \mid \frac{\left(k_{3}-k_{0}\right)-\left(k_{2}-k_{0}\right)}{e_{3}}-\frac{\left(k_{2}-k_{0}\right)-\left(k_{1}-k_{0}\right)}{e_{2}} \\
& \quad+\frac{\left(k_{2}-k_{0}\right) e_{1}}{e_{2}\left(e_{1}+e_{2}\right)}-\frac{k_{1}-k_{0}}{e_{2}} \mid \\
& =\left|\frac{k_{3}-k_{0}}{e_{3}}-\frac{\left(k_{2}-k_{0}\right)\left(e_{1}+e_{2}+e_{3}\right)}{e_{3}\left(e_{1}+e_{2}\right)}\right|
\end{aligned}
$$

Thus it may be seen that the conclusion is true for this case.

For the final step in the induction we begin by noting that

$$
\begin{gathered}
\sum_{p=1}^{n}\left|\frac{k_{p+1}-k_{p}}{e_{p+1}}-\frac{k_{p}-k_{p-1}}{e_{p}}\right| \geqq \sum_{p=1}^{n-1}\left|\frac{k_{p+1}-k_{0}}{\sum_{q=1}^{p+1} e_{q}}-\frac{k_{p}-k_{0}}{\sum_{q=1}^{p} e_{q}}\right| \\
+\frac{1}{e_{n+1}} \cdot\left(\sum_{q=1}^{n+1} e_{q}\right)\left|\frac{k_{n+1}-k_{0}}{\sum_{q=1}^{n+1} e_{q}}-\frac{k_{n}-k_{0}}{\sum_{q=1}^{n} e_{q}}\right|
\end{gathered}
$$

is true provided the last term of the left-hand member is greater than or equal to the sum of the last term of the right-hand member and

$$
\left(1-\frac{1}{e_{n}} \cdot \sum_{q=1}^{n} e_{q}\right)\left|\frac{k_{n}-k_{0}}{\sum_{q=1}^{n} e_{q}}-\frac{k_{n-1}-k_{0}}{\sum_{q=1}^{n-1} e_{q}}\right| .
$$

But this is true provided the sum of the last term of the left-hand member and

$$
\frac{1}{e_{n}} \cdot\left(\sum_{q=1}^{n-1} e_{q}\right)\left|\frac{k_{n}-k_{0}}{\sum_{q=1}^{n} e_{q}}-\frac{k_{n-1}-k_{0}}{\sum_{q=1}^{n-1} e_{q}}\right|
$$

is greater than or equal to the last term of the right-hand member. This last sum, is, by the triangle inequality, greater than or equal to 


$$
\begin{aligned}
& \mid \frac{\left(k_{n+1}-k_{0}\right)-\left(k_{n}-k_{0}\right)}{e_{n+1}}-\frac{\left(k_{n}-k_{0}\right)-\left(k_{n-1}-k_{0}\right)}{e_{n}} \\
& \quad+\frac{\left(k_{n}-k_{0}\right) \cdot \sum_{q=1}^{n-1} e_{q}}{e_{n} \cdot \sum_{q=1}^{n} e_{q}}-\frac{k_{n-1}-k_{0}}{e_{n}} \mid \\
& =\left|\frac{k_{n+1}-k_{0}}{e_{n+1}}-\frac{\left(k_{n}-k_{0}\right) \cdot \sum_{q=1}^{n+1} e_{q}}{e_{n+1} \cdot \sum_{q=1}^{n} e_{q}}\right| .
\end{aligned}
$$

Thus each of the inequalities is true. Hence Lemma 3.1.

Lemma 3.2. If $n$ is an integer greater than 2 and $k_{0}, k_{1}, \cdots, k_{n}$ is a number sequence and $s_{0}, s_{1}, \cdots, s_{n}$ is an increasing real number sequence, then

$$
\sum_{p=1}^{n-1}\left|\frac{k_{p+1}-k_{p}}{s_{p+1}-s_{p}}-\frac{k_{p}-k_{p-1}}{s_{p}-s_{p-1}}\right| \geqq \sum_{p=1}^{n-1}\left|\frac{k_{p+1}-k_{0}}{s_{p+1}-s_{0}}-\frac{k_{p}-k_{0}}{s_{p}-s_{0}}\right| .
$$

This result follows immediately from Lemma 3.1 by the transformation: $s_{p}-s_{p-1}=e_{p}$ for $p=1,2, \cdots, n$.

Lemma 3.3. If $v$ has bounded slope variation with respect to $u$ then $D_{u}^{-} v(t)$ exists for each $t$ in $(a, b]$ and $D_{u}^{+} v(t)$ exists for each $t$ in $[a, b)$.

Proof. Suppose $c$ is in $[a, b)$ and $\operatorname{limit}_{t \rightarrow c+}(v(t)-v(c)) /(u(t)-u(c))$ does not exist. Then there exists a positive number $\varepsilon$ such that if $r$ is in $(c, b)$ then there exists a number $s$ in $(c, r)$ for which

$$
\left|\frac{v(r)-v(c)}{u(r)-u(c)}-\frac{v(s)-v(c)}{u(s)-u(c)}\right| \geqq \varepsilon .
$$

It may be seen, then, that if $n$ is an integer greater than 2 there exists an increasing number sequence $s_{0}, s_{1}, \cdots, s_{n}$ with $s_{0}=c$ and each term in $[c, b]$ such that

$$
\sum_{p=1}^{n-1}\left|\frac{v\left(s_{p+1}\right)-v(c)}{u\left(s_{p+1}\right)-u(c)}-\frac{v\left(s_{p}\right)-v(c)}{u\left(s_{p}\right)-u(c)}\right| \geqq(n-1) \varepsilon .
$$

But from this inequality and Lemma 3.2 it follows that

$$
\sum_{p=1}^{n-1}\left|\frac{v\left(s_{p+1}\right)-v\left(s_{p}\right)}{u\left(s_{p+1}\right)-u\left(s_{p}\right)}-\frac{v\left(s_{p}\right)-v\left(s_{p-1}\right)}{u\left(s_{p}\right)-u\left(s_{p-1}\right)}\right| \geqq(n-1) \varepsilon .
$$


Since there exists an integer $n$ for which $(n-1) \varepsilon>V_{a}^{b}(d v / d u)$, this is a contradiction. Hence $D_{u}^{+} v(c)$ exists for each $c$ in $[a, b)$. An argument similar to that just given shows that $D_{u}^{-} v(c)$ exists for each $c$ in $(a, b]$. Hence Lemma 3.3.

LEMMA 3.4. Suppose $v$ has bounded slope variation with respect to $u$. If $t$ is in $(a, b]$, then $\int_{a}^{b} d R_{t} d v / d u$ exists and is equal to $D_{u}^{-} v(t)$. If $t$ is in $[a, b)$, then $\int_{a}^{b} d L_{t} d v / d u$ exists and is equal to $D_{u}^{+} v(t)$.

This lemma follows readily from Lemma 3.3 and the observation that, in each of the two equations implied by Lemma 3.4, each approximant for the right-hand member is an approximant for the lefthand member.

LEMMA 3.5. If $v$ has bounded slope variation with respect to $u$ then the functional $F$, given by

$$
F(x)=\int_{a}^{b} \frac{d x d v}{d u},
$$

is linear on its domain, the dv/du-integrable functions $x$, and these form a linear space.

Proof of lemma is not given.

Lemma 3.6. If $S$ is a step function and $v$ has bounded slope variation with respect to $u$ then

$$
\int_{a}^{b} \frac{d S d v}{d u} \text { exists. }
$$

This lemma follows from Definition 2.5 and Lemmas 3.4 and 3.5.

Lemma 3.7. If a normed linear space $A$ may be written as a direct sum $A=B \oplus C$ of two of its subspaces in such a way that

$$
\|\alpha\|=\operatorname{Max}\left\{\left\|\operatorname{Pr}_{1}(\alpha)\right\|,\left\|\operatorname{Pr}_{2}(\alpha)\right\|\right\}
$$

for each a in $A$, then

$$
\|F\|=\left\|F \circ P r_{1}\right\|+\left\|F \circ P r_{2}\right\|,
$$

for each bounded linear functional $F$ on $A$.

Proof of this lemma is not given. 
LEMMA 3.8. Suppose $h$ is subset of $[a, b]$ and $f$ and $g$ are mutually exclusive subsets of $h$ whose union is $h$. Suppose, moreover, that if $x$ is any function in $Q_{0}[a, b]$, then each of $x_{f}, x_{g}$, and $x_{h}$ is in $Q_{0}[a, b]$. If $F$ is a bounded linear functional from $Q_{0}[a, b]$ then each of $F_{f}, F_{g}$, and $F_{h}$ is a bounded linear functional and

$$
\left\|F_{f}\right\|+\left\|F_{g}\right\|=\left\|F_{h}\right\| \leqq\|F\| \text {. }
$$

This lemma is a mere application of Lemma 3.7.

4. Theorems. In this section a representation for the bounded linear functionals on $Q_{0}[a, b]$ in terms of the Hellinger integral is developed and a formula for their norms is given.

THEOREM 4.1. If $x$ is in $Q_{0}[a, b]$ and $v$ has bounded slope variation with respect to $u$, then $\int_{a}^{b} d x d v / d u$ exists and

$$
\left|\int_{a}^{b} \frac{d x d v}{d u}\right| \leqq\left\{V_{a}^{b} \frac{d v}{d u}+\left|D_{u}^{-} v(b)\right|\right\}\|x\|
$$

Proof. Let $S_{1}, S_{2}, S_{3}, \cdots$ be a sequence of step functions such that $\left\|S_{p}-x\right\|<1 / p$ if $p$ is a positive integer. Suppose $n$ is an integer greater than $1,\left\{t_{p}\right\}_{p=0}^{n}$ is a subdivision of $[a, b]$ and $q$ is a positive integer. Then, using summation by parts,

$$
\begin{aligned}
\sum_{p=1}^{n} & \frac{\left[S_{q}\left(t_{p}\right)-S_{q}\left(t_{p-1}\right)\right]\left[v\left(t_{p}\right)-v\left(t_{p-1}\right)\right]}{u\left(t_{p}\right)-u\left(t_{p-1}\right)} \\
= & -\sum_{p=1}^{n-1} S_{q}\left(t_{p}\right)\left\{\frac{v\left(t_{p+1}\right)-v\left(t_{p}\right)}{u\left(t_{p+1}\right)-u\left(t_{p}\right)}-\frac{v\left(t_{p}\right)-v\left(t_{p-1}\right)}{u\left(t_{p}\right)-u\left(t_{p-1}\right)}\right\} \\
& +S_{q}\left(t_{n}\right) \frac{v(b)-v\left(t_{n-1}\right)}{u(b)-u\left(t_{n-1}\right)} .
\end{aligned}
$$

It is thus evident that the left-hand member of this equation is, in absolute value, less than or equal to

$$
\left\|S_{q}\right\|\left\{V_{a}^{b} \frac{d v}{d u}+\left|\frac{v(b)-v\left(t_{n-1}\right)}{u(b)-u\left(t_{n-1}\right)}\right|\right\} \text {. }
$$

From this and Lemmas 3.3 and 3.6 one may conclude that

$$
\left|\int_{a}^{b} \frac{d S_{q} d v}{d u}\right| \leqq\left\|S_{q}\right\|\left\{V_{a}^{b} \frac{d v}{d u}+\left|D_{u}^{-} v(b)\right|\right\}
$$

(It is to be noted that this inequality holds true with $S_{q}$ replaced by any other function in $Q_{0}[a, b]$ for which the integral exists). If $m$ is an integer greater than $q$, then, since $\left\|S_{q}-S_{m}\right\|<2 / q$, it follows that 


$$
\left|\int_{a}^{b} \frac{d\left(S_{q}-S_{m}\right) d v}{d u}\right| \leqq \frac{2}{q}\left\{V_{a}^{b} \frac{d v}{d u}+\left|D_{u}^{-} v(b)\right|\right\} .
$$

Consequently, the sequence

$$
\left\{\int_{a}^{b} \frac{d S_{q} d v}{d u}\right\}_{q=1}^{\infty}
$$

is a Cauchy sequence and so has a sequential limit. Call this limit I. We now show that the approximants to $\int_{a}^{b} d x d v / d u$ tend, under refinement, to $I$.

There exists a number $B$ such that

$$
V_{a}^{b} \frac{d v}{d u}+\left|\frac{v(b)-v(t)}{u(b)-u(t)}\right|<B
$$

for each $t$ in $[a, b)$. Since $\left\|x-S_{p}\right\|<1 / p$ for $p=1,2, \cdots$, it follows that

$$
\left|\sum_{i=1}^{m} \frac{\left\{x\left(s_{i}\right)-S_{p}\left(s_{i}\right)-\left[x\left(s_{i-1}\right)-S_{p}\left(s_{i-1}\right)\right]\right\}\left[v\left(s_{i}\right)-v\left(s_{i-1}\right)\right]}{u\left(s_{i}\right)-u\left(s_{i-1}\right)}\right|<\frac{B}{p}
$$

for any subdivision $\left\{s_{i}\right\}_{i=0}^{m}$ of $[a, b]$ and any positive integer $p$. For each positive integer $p$ there exists a subdivision $D_{p}$ of $[a, b]$ such that if $\left\{s_{i}\right\}_{i=0}^{m}$ is any refinement of $D_{p}$ then

$$
\sum_{i=1}^{m} \frac{\left[S_{p}\left(s_{i}\right)-S_{p}\left(s_{i-1}\right)\right]\left[v\left(s_{i}\right)-v\left(s_{i-1}\right)\right]}{u\left(s_{i}\right)-u\left(s_{i-1}\right)}-\int_{a}^{b} \frac{d S_{p} d v}{d u} \mid<\frac{B}{p} .
$$

Since

$$
\left|\int_{a}^{b} \frac{d S_{p} d v}{d u}-I\right| \leqq \frac{2 B}{p} \quad \text { for } p=1,2, \cdots
$$

it follows that, for each positive integer $p$,

$$
\left|\sum_{i=1}^{m} \frac{\left[x\left(s_{i}\right)-x\left(s_{i-1}\right)\right]\left[v\left(s_{i}\right)-v\left(s_{i-1}\right)\right]}{u\left(s_{i}\right)-u\left(s_{i-1}\right)}-I\right|<\frac{4 B}{p}
$$

provided $\left\{s_{i}\right\}_{i=0}^{m}$ is a refinement of $D_{p}$. Hence $\int_{a}^{b} d x d v / d u$ exists and its value is $I$. That the integral satisfies the inequality of the conclusion may be seen from the parenthetical note above. Hence Theorem 4.1.

THEOREM 4.2. Suppose $v$ has bounded slope variation with respect to $u$ and $F$ is the functional defined by

$$
F(x)=\int_{a}^{b} \frac{d x d v}{d u}
$$


for each $x$ in $Q_{0}[a, b]$. Then $F$ is a bounded linear functional whose norm is $V_{a}^{b}(d v / d u)+\left|D_{u}^{-} v(b)\right|$.

Proof. It is clear from Lemma 3.5 and Theorem 4.1 that $F$ is linear and bounded and that the norm of $F$ does not exceed $V_{a}^{b}(d v / d u)+\left|D_{u}^{-} v(b)\right|$. We now construct a function $z$ in $Q_{0}[a, b]$ such that $\|z\|=1$ and $F(z)$ equals the sum of $\left|D_{u}^{-} v(b)\right|$ and the approximant for $V_{a}^{b}(d v / d u)$ corresponding to a preassigned subdivision of $[a, b]$.

Suppose $\left\{t_{p}\right\}_{p=0}^{n}$ is a subdivision of $[a, b]$ with $n>1$. Define $d_{p}$, for $p=1,2, \cdots,(n-1)$, by

$$
d_{p}=\frac{v\left(t_{p+1}\right)-v\left(t_{p}\right)}{u\left(t_{p+1}\right)-u\left(t_{p}\right)}-\frac{v\left(t_{p}\right)-v\left(t_{p-1}\right)}{u\left(t_{p}\right)-u\left(t_{p-1}\right)}
$$

if this expression is not zero and $d_{p}=1$ if the expression is zero. For $p=1,2, \cdots,(n-1)$, let $z_{p}$ be a function such that

$$
z_{p}(t)= \begin{cases}-\frac{u(t)-u\left(t_{p-1}\right)}{u\left(t_{p}\right)-u\left(t_{p-1}\right)} \cdot \frac{\left|d_{p}\right|}{d_{p}} & \text { for } t \text { in }\left[t_{p-1}, t_{p}\right] \\ -\frac{u\left(t_{p+1}\right)-u(t)}{u\left(t_{p+1}\right)-u\left(t_{p}\right)} \cdot \frac{\left|d_{p}\right|}{d_{p}} & \text { for } t \text { in }\left[t_{p}, t_{p+1}\right] \\ 0 \text { for } t \text { in }[a, b] \text { but not in }\left[t_{p-1}, t_{p+1}\right] .\end{cases}
$$

If $D_{u}^{-} v(b)=0$, let $z_{n}=R_{b}$. If $D_{u}^{-} v(b) \neq 0$ let $z_{n}=\left(D_{u}^{-} v(b) /\left|D_{u}^{-} v(b)\right|\right) R_{b}$. Finally, let $z=\sum_{p=1}^{n} z_{p}$ 。

Each of $z, z_{1}, z_{2}, \cdots, z_{n}$ is in $Q_{0}[a, b]$ and it may be verified that

$$
\int_{a}^{b} \frac{d z_{p} d v}{d u}=\left[\frac{v\left(t_{p+1}\right)-v\left(t_{p}\right)}{u\left(t_{p+1}\right)-u\left(t_{p}\right)}-\frac{v\left(t_{p}\right)-v\left(t_{p-1}\right)}{u\left(t_{p}\right)-v\left(t_{p-1}\right)}\right] \frac{\left|d_{p}\right|}{d_{p}}
$$

for $p=1,2, \cdots,(n-1)$ and $\int_{a}^{b}\left(d z_{n} d v / d u\right)=\left|D_{u}^{-} v(b)\right|$. Hence,

$$
\int_{a}^{b} \frac{d z d v}{d u}=\sum_{p=1}^{n-1}\left|\frac{v\left(t_{p+1}\right)-v\left(t_{p}\right)}{u\left(t_{p+1}\right)-u\left(t_{p}\right)}-\frac{v\left(t_{p}\right)-v\left(t_{p-1}\right)}{u\left(t_{p}\right)-u\left(t_{p-1}\right)}\right|+\left|D_{u}^{-} v(b)\right|
$$

If $t$ is in $\left[a, t_{1}\right]$, then

$$
|z(t)|=\left|-\frac{u(t)-u(a)}{u\left(t_{1}\right)-u(a)} \cdot \frac{\left|d_{1}\right|}{d_{1}}\right| \leqq 1 .
$$

If $t$ is in $\left[t_{n-1}, b\right)$, then

$$
|z(t)|=\left|-\frac{u(b)-u(t)}{u(b)-u\left(t_{n-1}\right)} \cdot \frac{\left|d_{n-1}\right|}{d_{n-1}}\right| \leqq 1 .
$$

If $p$ is one of $1,2, \cdots,(n-2)$ and $t$ is in $\left[t_{p}, t_{p+1}\right]$ then 


$$
|z(t)|=\left|-\frac{u(t)-u\left(t_{p}\right)}{u\left(t_{p+1}\right)-u\left(t_{p}\right)} \frac{\left|d_{p+1}\right|}{d_{p+1}}-\frac{u\left(t_{p+1}\right)-u(t)}{u\left(t_{p+1}\right)-u\left(t_{p}\right)} \frac{\left|d_{p}\right|}{d_{p}}\right| \leqq 1 .
$$

And $|z(b)|=1$. Hence $\|z\|=1$.

It may be inferred from the foregoing that the norm of $F$ is not less than $V_{a}^{b}(d v / d u)+\left|D_{u}^{-} v(b)\right|$. Hence Theorem 4.2.

THEOREM 4.3. If $F$ is a bounded linear functional from $Q_{0}[a, b]$ then there exist two functions $u$ and $v$, with $v$ having bounded slope variation with respect to $u$, such that

$$
F(x)=\int_{a}^{b} \frac{d x d v}{d u}
$$

for each $x$ in $Q_{0}[a, b]$.

Proof. Suppose $c$ is in $(a, b]$. If $r$ and $s$ are numbers such that $a<r<s<c$, then, by Lemma 3.8, $\left\|F_{(r, c)}\right\| \geqq\left\|F_{(s, c)}\right\| \geqq 0$. Consequently, limit $i_{t \rightarrow c-}\left\|F_{(t, c)}\right\|$ exists. Let $\lambda$ denote the function such that $\lambda(c)=\operatorname{limit}_{t \rightarrow c-}\left\|F_{(t, c)}\right\|$ for each number $c$ in $(a, b]$ and $\lambda(a)=0$. Similarly, let $\rho$ denote the function such that $\rho(c)=\operatorname{limit}_{t \rightarrow c+}\left\|F_{(c, t)}\right\|$ for each $c$ in $[a, b)$ and $\rho(b)=0$.

Now it may be seen from the definition of $\lambda$ and Lemma 3.8 that if $\left\{t_{p}\right\}_{p=0}^{n}$ is a subdivision of $[a, b]$, then

$$
\sum_{p=0}^{n} \lambda\left(t_{p}\right) \leqq\|F\| \text {. }
$$

A similar statement is true of $\rho$. Thus there exists a countable subset $M$ of $[a, b]$ such that if $t$ is in $[a, b]$ but not in $M$ then $\lambda(t)=\rho(t)=0$.

Let $u$ denote an increasing function such that (1) if $t$ is in $(a, b)$ and $\lambda(t)>0$, then $u(t)-u(t-)>0$, and (2) if $t$ is in $[a, b)$ and $\rho(t)>0$, then $u(t+)-u(t)>0$. For each $t$ in $[a, b]$ let $u_{t}$ denote the function such that $u_{t}(s)=0$ for $a \leqq s \leqq t$ and $u_{t}(s)=u(s)-u(t)$ for $t \leqq s \leqq b$. Let $v$ denote the function such that $v(t)=-F\left(u_{t}\right)$ for each $t$ in $[a, b]$.

Suppose $\left\{t_{p}\right\}_{p=0}^{n}$ is a subdivision of $[a, b]$ and $n>1$. Then, by the definition of $v$ and the linearity of $F$ there exists a number sequence $\left\{d_{p}\right\}_{p=1}^{n-1}$, with $\left|d_{p}\right|=1$ for $p=1,2, \cdots,(n-1)$, such that

$$
\begin{aligned}
& \sum_{p=1}^{n-1}\left|\frac{v\left(t_{p+1}\right)-v\left(t_{p}\right)}{u\left(t_{p+1}\right)-u\left(t_{p}\right)}-\frac{v\left(t_{p}\right)-v\left(t_{p-1}\right)}{u\left(t_{p}\right)-u\left(t_{p-1}\right)}\right| \\
& \quad=F\left(\sum_{p=1}^{n-1}\left[\frac{u_{t_{p+1}}-u_{t_{p}}}{u\left(t_{p+1}\right)-u\left(t_{p}\right)}-\frac{u_{t_{p}}-u_{t_{p-1}}}{u\left(t_{p}\right)-u\left(t_{p-1}\right)}\right] d_{p}\right) .
\end{aligned}
$$


It may be verified that the norm of the function which is the argument of $F$ in the right-hand member of the equation is 1 . Consequently the left-hand member is less than or equal to $\|F\|$. Thus it may be inferred that $v$ has bounded slope variation with respect to $u$.

Let $G$ denote the bounded linear functional such that

$$
G(x)=\int_{a}^{b} \frac{d x d v}{d u}
$$

for each $x$ in $Q_{0}[a, b]$. Suppose $c$ is in $(a, b]$. By Lemma 3.4

$$
\begin{aligned}
G\left(R_{c}\right) & =D_{u}^{-} v(c) \\
G\left(R_{c}\right) & =\operatorname{limit}_{t \rightarrow c-} \frac{v(c)-v(t)}{u(c)-u(t)} \\
& =\operatorname{limit}_{t \rightarrow c-} F\left(\frac{u_{t}-u_{c}}{u(c)-u(t)}\right) .
\end{aligned}
$$

For $t$ in $(a, c)$, one has

$$
\left|\frac{u_{t}(s)-u_{c}(s)}{u(c)-u(t)}-R_{c}(s)\right| \leqq\left\{\begin{array}{l}
0 \text { if } s \text { is in }[a, t] \\
\frac{u(c-)-u(t)}{u(c)-u(t)} \text { if } s \text { is in }(t, c) \\
0 \text { if } c \leqq s \leqq b
\end{array}\right.
$$

so that

$$
\begin{aligned}
\left|\frac{v(c)-v(t)}{u(c)-u(t)}-F\left(R_{c}\right)\right| & =\left|F_{(t, c)}\left(\frac{u_{t}-u_{c}}{u(c)-u(t)}-R_{c}\right)\right| \\
& \leqq\left\|F_{(t, c)}\right\| \cdot \frac{u(c-)-u(t)}{u(c)-u(t)} \leqq\left\|F_{(t, c)}\right\| .
\end{aligned}
$$

Now limit t $\rightarrow c-\left\|F_{(t, c)}\right\|=\lambda(c)$. But if $\lambda(c)>0$, then $u(c)-u(c-)>0$ so that

$$
\operatorname{limit}_{t \rightarrow c-} \frac{u(c-)-u(t)}{u(c)-u(t)}=0 .
$$

So, whether $\lambda(c)$ is positive or zero, one has that

$$
\operatorname{limit}_{t \rightarrow c-}\left|\frac{v(c)-v(t)}{u(c)-u(t)}-F\left(R_{c}\right)\right|=0 .
$$

Hence $F\left(R_{c}\right)=G\left(R_{c}\right)$ for each $c$ in $(a, b]$. A similar argument shows that $F\left(L_{c}\right)=G\left(L_{c}\right)$ for each $c$ in $[a, b)$. Therefore $F(S)=G(S)$ for every step function $S$. Thus, $F=G$. Hence Theorem 4.3. Clearly, the norm of $F$ is given by the expression appearing in Theorem 4.2. 


\section{REFERENCE}

1. R. E. Lane, The integral of a function with respect to a function, Proc. Amer. Math. Soc. 5 (1954), 59-66.

Received February 5, 1966. 



\section{PACIFIC JOURNAL OF MATHEMATICS}

\section{EDITORS}

\author{
H. SAMELSON \\ Stanford University \\ Stanford, California \\ J. P. JANS \\ University of Washington \\ Seattle, Washington 98105
}

\section{J. DugundJI}

University of Southern California Los Angeles, California 90007

RICHARD ARENS

University of California

Los Angeles, California 90024

\section{ASSOCIATE EDITORS}
E. F. BECKENBACH
B. H. NeumanN
F. WOLF
K. YOSIDA

\section{SUPPORTING INSTITUTIONS}

\author{
UNIVERSITY OF BRITISH COLUMBIA \\ CALIFORNIA INSTITUTE OF TECHNOLOGY \\ UNIVERSITY OF CALIFORNIA \\ MONTANA STATE UNIVERSITY \\ UNIVERSITY OF NEVADA \\ NEW MEXICO STATE UNIVERSITY \\ OREGON STATE UNIVERSITY \\ UNIVERSITY OF OREGON \\ OSAKA UNIVERSITY \\ UNIVERSITY OF SOUTHERN CALIFORNIA
}

\author{
STANFORD UNIVERSITY \\ UNIVERSITY OF TOKYO \\ UNIVERSITY OF UTAH \\ WASHINGTON STATE UNIVERSITY \\ UNIVERSITY OF WASHINGTON \\ AMERICAN MATHEMATICAL SOCIETY \\ CHEVRON RESEARCH CORPORATION \\ TRW SYSTEMS \\ NAVAL ORDNANCE TEST STATION
}

Mathematical papers intended for publication in the Pacific Journal of Mathematics should be typewritten (double spaced). The first paragraph or two must be capable of being used separately as a synopsis of the entire paper. It should not contain references to the bibliography. Manuscripts may be sent to any one of the four editors. All other communications to the editors should be addressed to the managing editor, Richard Arens at the University of California, Los Angeles, California 90024 .

50 reprints per author of each article are furnished free of charge; additional copies may be obtained at cost in multiples of 50 .

The Pacific Journal of Mathematics is published monthly. Effective with Volume 16 the price per volume (3 numbers) is $\$ 8.00$; single issues, $\$ 3.00$. Special price for current issues to individual faculty members of supporting institutions and to individual members of the American Mathematical Society: $\$ 4.00$ per volume; single issues $\$ 1.50$. Back numbers are available.

Subscriptions, orders for back numbers, and changes of address should be sent to Pacific Journal of Mathematics, 103 Highland Boulevard, Berkeley 8, California.

Printed at Kokusai Bunken Insatsusha (International Academic Printing Co., Ltd.), No. 6, 2-chome, Fujimi-cho, Chiyoda-ku, Tokyo, Japan.

PUBLISHED BY PACIFIC JOURNAL OF MATHEMATICS, A NON-PROFIT CORPORATION

The Supporting Institutions listed above contribute to the cost of publication of this Journal, but they are not owners or publishers and have no responsibility for its content or policies. 


\section{Pacific Journal of Mathematics \\ Vol. 20, No. $2 \quad$ October, 1967}

Edward Dewey Davis, Ideals of the principal class, $R$-sequences and a certain monoidal transformation ............................. 197

Richard Mansfield Dudley, Sub-stationary processes ................ 207

Newton Seymour Hawley and M. Schiffer, Riemann surfaces which are doubles of plane domains ......................... 217

Barry E. Johnson, Continuity of transformations which leave invariant certain translation invariant subspaces ................... 223

John Eldon Mack and Donald Glen Johnson, The Dedekind completion of

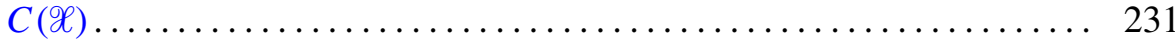

K. K. Mathur and R. B. Saxena, On the convergence of quasi-Hermite-Fejér interpolation................................... 245

H. D. Miller, Generalization of a theorem of Marcinkiewicz............ 261

Joseph Baruch Muskat, Reciprocity and Jacobi sums ............... 275

Stelios A. Negrepontis, On a theorem by Hoffman and Ramsay .......... 281

Paul Adrian Nickel, A note on principal functions and multiply-valent canonical mappings .............................. 283

Robert Charles Thompson, On a class of matrix equations ............. 289

David Morris Topping, Asymptoticity and semimodularity in projection lattices ........................................ 317

James Ramsey Webb, A Hellinger integral representation for bounded linear functionals

Joel John Westman, Locally trivial $C^{r}$ groupoids and their representations...

Hung-Hsi Wu, Holonomy groups of indefinite metrics 